\title{
MARMARIS MÜZESINDEN ÜÇ UZUN CAM UNGUENTARIUM
}

\section{EMEL ERTEN}

Son ylllarda, Marmaris Müzesi tarafından, yerel bir satıcıdan üç adet uzun cam unguentarium satın alınmıştır. Bunların buluntu yeri bilinmemekle birlikte, çok benzer ölçülere, form ve cam özelliklerine sahip olmaları bakımından aynı mezar konteksti içinde, bir arada ele geçmiş olmaları gerekmektedir (Res. 1a-b, 2a-b, 3a-b, kat. no. 1-3).

Unguentarium, (özellikle tüp biçimli ve şamdan biçimli tipler) cam üflemeciliğinin yaklaşık olarak İ.Ö. 25 yllında icat edilmesinden sonra Roma camcılığında en yaygın görülen form haline gelmiştir ${ }^{1}$. Roma günlük yaşamında sıkça kullanılan kokulu yağların, parfümlerin, merhemlerin yani, "unguent"lerin saklanmasına yaradığı için bu isimle tanınmaktadır ${ }^{2}$. Unguentarium, iç kalıp tekniği ile üretilmiş olan cam formların (aryballos, alabastron, amphoriskos, oinokhoe) üfleme tekniğinde yapılmış karșllığı olarak değerlendirilebilir. Basit cam formu olarak Roma İmparatorluğu'nun batı ve doğu topraklarında geniş bir yayılım gösterir.

${ }^{1}$ Cam üflemeciliğinin bulunuşu ve yayılımı konusunda bkz.: Avigad, N. "Expedition at Nahal David", Israel Exploration Journal XII (1962), s. 169-183; Avigad, N. "Excavation in the Jewish Quarter of the Old City of Jerusalem", Israel Exploration Journal XXII (1972), s. 193-200 Mazar, B. - Dunayevsky, I. "Ein Gedi -Third Season of Excavations, Israel Exploration Journal XIV (1964), s. 121-130 ; Israeli, Y. "The Invention of Blowing", Roman Glass - Two Centuries of Art and Invention (ed. M. Newby - K. Painter), London 1991, s. 46-55, özellikle Stern, E. M. "Roman Glassblowing in a Cultural Context", American Journal of Archaeology 103.3 (1999), s. 441-484.

2 İçerdiği orijinal madde ile bir arada saptanmış çok fazla sayıda unguentarium bulunmamakla birlikte (bkz.: Crivelli, A. I Vetri Romani di Locarno, 1979, p. 26 veya Greenewalt Jr., - C. H. - Sullivan, D. G. -Ratté, C. J. - Howe, T. H. "Sardis 1981 and 1982" Türk Arkeoloji Dergisi XXVI.2 (1983), s. 182-183), unguent'lerin içerdiği maddeler konusunda elimizde yeterli yazılı kaynaklar vardır : Plinius, Historia Naturalis'te (XIII.1-25) bu konuda ayrınulı bilgilere yer verir. Unguent yapımında en çok kullanılan otlar safran, mercankőssk, kına, süsen ve nanedir Buna ek olarak, çeşitli gül türleri, bal ve yabani üzüm bile unguent üretiminde kullanılmıştur. Unguent ve ilaç yapımında kullanılan otlar konusunda ayrınulı bilgi için: bkz. Scarborough, J. "Drugs and Medicines in the Roman World", Expedition 38.2 (1996), s. 38-51. 
Ölümden sonra yaşam konusundaki Roma inancına göre, ölen kişinin mezarında kendini evinde hissetmesi için çaba harcanmaktadır ${ }^{3}$. Bu, Roma mezarlarında unguentarium ele geçmesinin' nedenlerinden biridir. Öte yandan, diğer bir amaç da mezarların güzel kokmasını sağlamak olarak açıklanmaktadır ${ }^{4}$.

Uzun unguentarium tipi, sivri ve masif ayakları ile tümüyle ayakta duramaz özelliktedir. Bu durumda, işlevlerinin "unguent" saklamak kadar taşımak olduğu da anlaşılmaktadır. Bugün bile ayakta duramayan parfüm şişesi geleneği hala bir ölçüde yaşamaktadır (Res. 4). Roma'da Villa Farnesina'da saptanan bir duvar resmi üzerinde elinde iki şişe ile parfüm döken bir kadın betimlenmiştir (Res. 5) ${ }^{5}$. Figürün sol elinde tuttuğu parfüm şişesinin bir uzun tipte bir unguentarium olması mümkün görünmektedir. Marlupo'daki bir mezarda yer alan duvar resminde de bir geniş gümüs kase içine yerleştirilmiş cam unguentarium örnekleri bulunmaktadır (res. 6) ${ }^{6}$. Bütün bunlar, Roma günlük yaşantısında bu formun yaygınlığını göstermektedir. Bunun yanısıra, uzun unguentarium tipinin mezar armağanları olarak da sunulmuş olması gerekmektedir. Marmaris Müzesi örneklerinin bu denli iyi korunabilmiş olmaları, onların bir yerleşim yerinde değil, bir mezarın korunaklı ortamı içinde günümüze ulaştklarını düşündürmektedir.

C.Isings, uzun unguentarium tipinin (Form 9-a) oldukça ender görüldüğünü belirtmekle birlikte, bat Roma buluntu yerlerinden ele geçen örneklerin yer aldığı bir sıralama yapmıştır ${ }^{7}$. Bu tip, ne tüp ne de şamdan biçimli unguentaria kadar yaygın değilse de, günümüzde C.Isings'in listesine eklenecek yeni örnekler de saptanmıştur. Ancak, ne yazık ki, bunların çoğunun buluntu yerleri bilinmemektedir ${ }^{8}$.

\footnotetext{
${ }^{3}$ Toynbee, J. M. C. Death and Burial in the Roman World, Baltimore and London 1996, s. 37-38.

${ }^{4}$ Hayes, J. W. Handbook of Mediterranean Roman Pottery, London 1997, s. 84.

${ }^{5}$ Ramage,N. H. -Ramage, A. Roman Art-Romulus to Constantine, New Jersey 1991, fig. 3.28 , s. 98.

${ }^{6}$ Naumann-Steckner, F. "Depictions of Glass in Roman Wall Paintings", Roman Glass- Two Centuries of Art and Invention (ed. by M. Newby - K. Painter) London 1991, pl. XXIV.a , s. 88, 94.

${ }^{7}$ Isings, C. Roman Glass from Dated Finds, Groningen 1957, s. $24-25$.

${ }^{8}$ Auth, S. H. Ancient Glass at the Newark Museum, Newark 1976, no. 359, s. 204 (cam ipliği süslemeli ); von Saldern, A. - Nolte, B. - La Baume P. - Haevernick, T.E. Gläser der Antike Sammlung Erwin Oppenländer, no. 639, s. 220 ; Hayes, J.W. Roman and Pre-Roman Glass in the Royal Ontario Museum, Toronto 1975, no. 103, pl. 10, s. 52; Crivelli, p. 29 (Muralto Necropolis'inden bir buluntu, Villa Liverpool) ; The National Archaeological Museum - Naples 1982
} 
Uzun unguentarium tipinin doğudan tanınan örnekleri ise, Kıbrıs ${ }^{9}$, Hirvatistan'daki Cautat (Epidaurum) ${ }^{10}$ ve belki de Suriye-Filistin bölgesinden gelmektedir ${ }^{11}$. Özellikle de Epidaurum unguentarium'u Marmaris Müzesi örnekleri ile form, renk ve ölçüleri bakımından yakın benzerlik göstermektedir (Res. 7)

Anadolu'da da aynı tipin saptanmış bazı örnekleri bulunmaktadır. Afyon Müzesi cam koleksiyonunda ağız kısmı korunamamış olan bir benzer unguentarium yer almaktadır ${ }^{12}$. Bu eserin buluntu yeri belli olmamakla birlikte, yine bir Anadolu buluntusu olması gerekmektedir. Bir diğer benzer unguentarium ise, İstanbul'da Türkiye Şişe ve Cam Fabrikaları A.Ş. koleksiyonundadır (Res. 8) ${ }^{13}$. Yine İstanbul'daki Sadberk Hanım Müzesi koleksiyonunda da üç adet uzun unguentarium yer almaktadır ${ }^{14}$. Berlin'deki Staatlichen Museum'da bulunan uzun unguentarium'un da bir Anadolu buluntusu olduğu söylenmektedir ${ }^{15}$. Bütün bu örnekler aslında, Marmaris'tekilerden

(müze rehberi), no. 3, s. 80-81; Özyiğit, S. "Hellenistik ve Roma Dönemlerinden bir Kap Formu: Unguentarium" Tombak 4 (1995), no .6, s. 20 ; Harden, D. B. - Hellenkemper H. - Painter, K. Whitehouse, D. Glass of the Caesars, Milan 1987, no.52, s.120 (Cumae, Italya'dan); Shining Vessels - Ancient Glass from Greek, Roman and Islamic Times (Fortuna Fine Arts Ltd. - Satı̧ Kataloğu) . New York 1991 , no. 163, s. 88-89 ; Fleming. S.J. "Early Imperial Glass at the University of Pennsylvania Museum", Expedition 38.2 (1996), fig. 15 A,B , s. 22 (koyu mavi üzerine beyaz spiral süslemeli) .

${ }^{9}$ Vessberg, O. "Roman Glass in Cyprus" Opuscula Archaeologica 7 (1952), pl .VII. 43-45, s. 132,135 .

${ }^{10}$ Trasparenze Imperiali -Vetri Romani dalla Croazia (katalog ), Rome - Milan 1997, no. 61, s. 83,121 .

${ }^{11}$ Bir örneğin Suriye kökenli olduğu ve Lübnan'da satun alındığı sōylenmektedir: Glass from the Ancient World - R. W. Smith Collection , New York 1957, no. 157, p. 92-93; bir diğeri ise, Emesa buluntusudur: Barag, D. Glass Vessels of the Roman and Byzantine Periods in Palestine, Jerusalem 1970 (yayınlanmamıs tez, İbranice), pl. 21. I, 94, Lightfoot, C.S. A Catalogue of Glass Vessels in Afyon Museum, BAR International Series 530, Oxford 1989, s. 24 ; Ashdod kaz1larında bir kaide parçası saptanmışur : Barag, D. "The Glass Vessels", in: Dothan, M. Ashdod IIIII. The Second and Third Seasons of Excavations 1963, 1965: Soundings in 1967, Atiqot (English Series) 1971, no. 13, fig. 105, s. 204.

${ }^{12}$ Lightfoot 1989, no. 5 , pl. 1, s. 24, 74.

${ }^{13}$ Canav, Ü. Türkiye Şişe ve Cam Fabrikalan A.Ș. Cam Eserler Koleksiyonu, İstanbul 1985. no. 37, s. 44. Aynı eserin bir diğer resminin yer aldığı yayın : Küçükerman, Ö. Cam ve Çağdaş Tasarım İçindeki Yeri - Glass and its Place in Contemporary Design, İstanbul 1978, no. 21, s. 70.

${ }^{14} \mathrm{Bu}$ unguentarium ōrnekleri daha ónce Kocabas koleksiyonunda yer almaktaydılar: Y. Akat, N. Fıratlı, H. Kocabaș, Hüseyin Kocabaş Koleksiyonu Cam Eserler Kataloğu / Catalogue of Glass in the Hüseyin Kocabaş Collection, İstanbul 1984, no. 164-165-166, res. 66, 67-a, 67-b, s. 28,59 .

${ }^{15}$ Kunisch, N. "Neu erworbene antike Gläser der Antikenabteilung der Staatlichen Museen Berlin", Archaologischer Anzeiger (1967), abb. 10, p. 184-185. 
biraz farklı özelliklere sahiptirler. Boyunları ile gövdelerinin birleştiği yerde bir boğum bulunmamaktadır. Ayrıca, Türkiye Şişe ve Cam Fabrikaları A.Ş. koleksiyonundaki unguentarium parlak mavi renkte camdan yapılmıştur. $\mathrm{Bu}$, Roma Erken İmparatorluk Dönemi için tipik bir özellik olmakla birlikte, Afyon ve Marmaris örneklerinin doğal ya da renklendirilmemiş camdan yapılmış oldukları görülmektedir. Buna karşılık, Sadberk Hanım Müzesi koleksiyonu örnekleri de renkli band ya da cam ipliği süslemelerine sahiptirler. Bu farklılıklara karşın, genel form özellikleri bakımından, her birini yine de aynı genel tip (Isings, Form 9-a) kapsamında değerlendirmek olasıdır.

Uzun cam unguentarium tipinin tüm örnekleri, İ.S. 1. yüzyıla veya 2. yüzyılın başlarına tarihlenmektedir. Bu, cam üflemeciliğinin artık ticari bir etkinlik durumuna geldiği ve Roma İmparatorluğu çapında bir girişimcilik alanı niteliği taşımaya başladığı bir dönemdir. Artık camcılık Suriye-Filistin bölgesine özgü bir yerel el sanat olmaktan çıkmış ve evrensel bir hal almış$\operatorname{ur}^{16}$.

İ.S. 1. ve 2. yüzyllarda doğuya oranla batı Roma topraklarında camcılığın daha gelişkin olduğu genel olarak kabul edilmektedir ${ }^{17}$. Ancak yine de form ve süsleme bakımından daha gösterişsiz ürünler vermekle birlikte, doğuda da dönemin teknik ve artistik yaklaşımlarını bir ölçüye kadar izlemek ve kesintisiz bir cam üretiminin varlığını saptamak olasıdır.

Bu genel çerçeve içinde, Marmaris Müzesi uzun cam unguentarium örnekleri, bat Roma topraklarında da iyi tanınan ve kimi zaman gösterişli süslemelere de sahip olan bir tipin, daha sade (süslemesiz olmaları renklendirilmemiş camdan yapılmaları bakımından) Roma erken imparatorluk dönemine ait doğulu temsilcileridir.

${ }^{16}$ Stern 1999, s. 442.

${ }^{17}$ Stern, E.M. Ancient Glass at the Fondation Custodia - Collection Frits Lugt -Paris, Groningen 1977, s. 155; örneğin, bau kōkenli uzun unguentaria arasında bir cameo cam oornekler bile bulunmaktadır. Bunlardan biri şimdi İspanya'da Ortiz koleksiyonundadır: Whitehouse, D. "Cameo Glass", Roman Glass - Two Centuries of Art and Invention (ed. by M. Newby- K. Painter) London 1991, pl. VI, VII a-b, p. 25, 29; diğeri ise İtalya'daki Torre di Siena'da bulunmuştur ve Floransa Museo Archeologico Nazionale koleksiyonundadır: Whitehouse 1991, s. 25, Fleming 1996, fig. 18, s. 23. 


\section{KATALOG}

1. Marmaris Müzesi Env. No.: 9.10 .99

Res. I a-b

Yükseklik: $9.5 \mathrm{~cm}$.; çap (ağız): $2 \mathrm{~cm}$.

Doğal yeşil cam, yüzeyde kahverengi ve gökkuşağı irizasyon ve aşınmalar.

Ağız kenarı içe doğru katlandıktan sonra düzleştirilmiş; silindir boyun altta bir boğumla uzun ve damla biçimli gövdeye bağlanmakta. Sivri ve içi dolu bir damlacık biçiminde dip.

Serbest üfleme.

Süslemesiz.

2. Marmaris Müzesi Env. No.: 9.11 .99

Res. 2 a-b

Yükseklik: $9.5 \mathrm{~cm}$.; çap (ağız): $2 \mathrm{~cm}$.

Doğal yeşil cam, yüzeyde kahverengi ve gökkuşağı irizasyon ve aşınmalar.

Ağız kenarı içe doğru katlandıktan sonra düzleştirilmiş; silindir boyun altta bir boğumla uzun ve damla biçimli gövdeye bağlanmakta. Sivri ve içi dolu bir damlacık biçiminde dip.

Serbest üfleme.

Süslemesiz.

3. Marmaris Müzesi Env. No. : 9.12 .99

Res. 3 a-b

Yükseklik : $10.5 \mathrm{~cm}$. ; çap (ağız) : $2 \mathrm{~cm}$.

Doğal yeşil cam, yüzeyde kahverengi ve gökkuşağı irizasyon ve aşınmalar.

Ağız kenarı içe doğru katlandıktan sonra düzleştirilmiş; silindir boyun altta bir boğumla uzun ve damla biçimli gövdeye bağlanmakta. Sivri ve içi dolu bir damlacık biçiminde dip.

Serbest üfleme.

Süslemesiz. 
